\title{
PROCESSAMENTO E UTILIZAÇÃo DA POLPA DE CAJÁ (Spondias mombin L.)
}

\author{
CYNTIA LADYANE ALVES DE MOURA* \\ GUSTAVO ADOLFO SAAVEDRA PINTO** \\ RAIMUNDO WILANE DE FIGUEIREDO***
}

\begin{abstract}
Esta revisão teve como objetivo reunir informações contidas na literatura científica nacional e internacional sobre as características físicas, físico-químicas e sensoriais da polpa de cajá e seus produtos derivados, como sucos, néctares e bebidas fermentadas. Verificouse a necessidade de organizar ações de pesquisa que visem aumentar o conhecimento sobre as características nutricionais dessa fruta, bem como sobre o desenvolvimento de novos processos tecnológicos ou ajustes naqueles já existentes, a fim de permitir o surgimento de novos produtos e a ampliação de mercados, o que por consequência levaria ao adensamento e estruturação da cadeia produtiva.
\end{abstract}

PALAVRAS-CHAVE: Spondias mombin L.; CAJÁ; POLPA DE FRUTA.

* Engenheira de Alimentos, Mestre em Ciência e Tecnologia de Alimentos, Doutoranda em Biotecnologia Industrial, Bolsista da Embrapa Agroindústria Tropical, Fortaleza, CE (e-mail: cyntialady@yahoo.com.br).

** Químico, Doutor em Tecnologia de Processos Químicos e Bioquímicos, Pesquisador da Embrapa Agroindústria Tropical, Fortaleza, CE (e-mail: gustavo@cnpat.embrapa.br).

*** Engenheiro Agrônomo, Doutor em Ciência de Alimentos, Professor, Departamento de Tecnologia de Alimentos, Universidade Federal do Ceará, Fortaleza, CE (e-mail: figueira@ufc.br). 


\section{INTRODUÇÃo}

As espécies frutíferas nativas das diversas regiões brasileiras têm despertado a atenção de cientistas e pesquisadores, que perceberam não só seu grande potencial para exploração comercial racional, mas também para exportação (LEDERMAN et al., 1992).

A cajazeira (Spondias mombin L.), espécie frutífera da família Anacardiaceae, encontra-se dispersa nas regiões tropicais da América, da África e da Ásia. No Brasil, a cajazeira é encontrada principalmente nos estados do Norte e Nordeste. Seus frutos, conhecidos como cajá, cajá verdadeiro, cajá-mirim ou taperebá são muito utilizados na confecção de polpas, sucos, picolés, sorvetes, néctares e geleias de excelente qualidade e valor comercial. A cajazeira ainda não é cultivada em escala comercial significativa, sendo considerada planta em domesticação e de exploração extrativa. Mesmo assim, a cada ano, sua participação cresce no agronegócio da região Nordeste, principalmente pela comercialização dos seus frutos para consumo como fruta fresca e processamento de polpa (SACRAMENTO e SOUZA, 2000).

A procura pelos frutos da cajazeira deve-se principalmente às boas características para industrialização, aliadas ao aroma e sabor agradáveis. Em virtude da ausência de plantios racionais, em época de safra é comercializada principalmente em feiras livres para consumo in natura ou para fabrico de polpa congelada, sorvete, suco e geleia. Na zona da mata do Nordeste, a safra concentrase nos meses de maio a julho, quando é comum sua comercialização ao longo das rodovias, embora esporadicamente ainda possam ser encontradas plantas com frutos em setembro (SACRAMENTO e SOUZA, 2000).

A polpa de cajá, produto recente no mercado nacional, não atende às necessidades do mercado interno, ficando ainda muito restrita às regiões Norte e Nordeste (SAMPAIO et al., 2005). Portanto, existe amplo mercado potencial a ser explorado.

A polpa de cajá vem sendo "exportada" para outras regiões brasileiras, havendo mercado assegurado para seu consumo na forma de suco e sorvete. No entanto, três fatores limitam a sua industrialização, a sazonalidade, a perecibilidade e o fato da cajazeira não ser cultivada em escala comercial significativa (MATA, BRAGA e SILVA, 2003; SACRAMENTO e SOUZA, 2000). $A$ perecibilidade dos frutos corresponde às alterações fisiológicas que ocorrem depois de sua formação e crescimento na planta mãe. A partir dessa etapa, todo o processo deve ser rápido a fim de se evitar contaminações e volatilização dos componentes que dão sabor e aroma característicos ao fruto. A sazonalidade corresponde ao período de tempo em que as plantas produzem seus frutos. Sacramento e Sousa (2000) reportaram que a época de safra varia de acordo com a região produtora, sendo de maio a julho na Paraíba; entre janeiro e março no Ceará; março a maio no Sul da Bahia, agosto a dezembro em Belém e dezembro a fevereiro em Manaus e Rio Branco.

O objetivo deste trabalho foi reunir informações contidas na literatura científica nacional e internacional sobre as características da polpa de cajá e seus produtos derivados.

\section{CARACTERÍSTICAS DA FRUTA E SUA PÓS-COLHEITA}

O fruto da cajazeira caracteriza-se como drupa (fruto carnoso, com apenas uma semente) de 3 a $4 \mathrm{~cm}$ de comprimento, ovóide ou oblongo, achatado na base, de cor variando do amarelo ao alaranjado. A casca é fina e lisa e a polpa pouco espessa e suculenta (também variando do amarelo ao alaranjado) apresenta sabor ácido-adocicado e muito agradável. O endocarpo ou caroço é grande, de cor branca, súbero-lignificado e enrugado, que pode conter de zero a cinco sementes/endocarpo. Os frutos das espécies do gênero Spondias são nuculânios elipsóides ou globosos, perfumados, com mesocarpo carnoso, amarelo e sabor agridoce (VIEIRA NETO, 2002).

Os frutos da cajazeira recém-colhidos têm peso variando entre 4,8 e 37,4 g (SACRAMENTO 
e SOUZA, 2000), contudo, Soares, Gomes e Carneiro (2006) apontam que de forma geral, o peso médio é de 9,9 g. Bosco et al. (2000), apud Soares, Gomes e Carneiro (2006) propuseram classificação para os frutos baseada em sua massa, sendo pequenos se inferior a $12 \mathrm{~g}$; médios, entre 12 e $15 \mathrm{~g}$ e grandes acima desse valor. Diferentes autores relataram o comprimento do fruto variando de 29,3 a 44,0 mm, enquanto que o diâmetro apresenta amplitude de 18,3 a 33,0 mm (Tabela1).

Apesar da fina camada de polpa do cajá, o rendimento em peso é alto devido à baixa densidade do caroço (embora volumoso). De acordo com Sacramento e Souza (2000), as proporções de casca e endocarpo variam de 8,4 a $18,7 \%$ e de 15,7 a $31,1 \%$, respectivamente, com rendimento acima de $60 \%$ em polpa que pode chegar a valores próximos a $80 \%$ (Tabela 1).

\section{TABELA 1 - CARACTERÍSTICAS FÍSICAS E RENDIMENTO EM POLPA DOS FRUTOS DE CAJÁ}

\begin{tabular}{|c|c|c|c|c|}
\hline \multirow[b]{2}{*}{$\begin{array}{l}\text { Comprimento } \\
(\mathrm{mm})\end{array}$} & \multicolumn{3}{|c|}{ CARACTERÍSTICAS } & \multirow[b]{2}{*}{ Referências } \\
\hline & $\begin{array}{l}\text { Diâmetro } \\
(\mathrm{mm})\end{array}$ & $\begin{array}{l}\text { Peso total } \\
\text { (g) }\end{array}$ & $\begin{array}{l}\text { Rendimento } \\
\text { em polpa (\%) }\end{array}$ & \\
\hline 33,7 & $18,3-26,8$ & 9,9 & 72,6 & Soares, Gomes e Carneiro, 2006 \\
\hline 44,0 & 33,0 & 20,0 & - & Dias, Schwan e Lima, 2003 \\
\hline $39,7-43,1$ & $28,1-32,2$ & $15,9-19,9$ & - & Vieira Neto, 2002 \\
\hline 43,1 & 32,2 & 19,92 & 81,7 & Alves, Filgueiras e Moura, 2000 \\
\hline 36,75 & 29,11 & 15,58 & - & Costa, 1998 \\
\hline
\end{tabular}

Sampaio (2002) e Alves, Filgueiras e Moura (2000) procuraram avaliar o efeito do amadurecimento dos frutos sobre as características da polpa de cajá, estabelecendo abordagens diferentes. Sampaio (2002) correlacionou os dados físico-químicos com a respiração dos frutos, dividindo os estádios de maturação em: inicial, pré-climatérico, mínimo climatérico, máximo climatérico e pós-climatérico. Alves, Filgueiras e Moura (2000) correlacionaram as análises à cor da casca do fruto, sendo os parâmetros avaliados nos estádios: verde, predominantemente verde, predominantemente amarelo e amarelo. No estudo realizado por Sampaio (2002) foi usado o método eudimétrico adaptado para medir as concentrações de $\mathrm{CO}_{2}$ e $\mathrm{O}_{2}$ de atmosferas controladas e modificadas. A produção máxima de $\mathrm{CO}_{2}$ foi de $54 \mathrm{~mL} \cdot \mathrm{kg}^{-1} \cdot \mathrm{h}^{-1}$, enquanto o consumo máximo de $\mathrm{O}_{2}$ foi de $49 \mathrm{~mL} \cdot \mathrm{kg}^{-1} \cdot \mathrm{h}^{-1}$. O Quociente Respiratório (QR) apresentou média de $0,92 \pm 0,17$. Os frutos de cajazeira revelaram padrão de atividade respiratória similar a dos frutos climatéricos. $\mathrm{A}$ tendência da respiração pós-colheita em frutos de cajazeira, medida pelo monitoramento das taxas de produção de $\mathrm{CO}_{2}$ e absorção de $\mathrm{O}_{2}$, evidenciou padrão de atividade respiratória similar a dos frutos climatéricos.

O climatério pode ser definido como o período da ontogenia de certos frutos, durante o qual diversas mudanças bioquímicas se iniciam pela produção autocatalítica de etileno, marcando a transição entre o desenvolvimento à senescência e envolvendo aumento na respiração e condução ao amadurecimento. O termo "climatérico" deve ser, portanto, aplicado ao total de mudanças envolvidas nessa fase crítica da vida do fruto, desencadeadas pelo etileno, e durante a qual muitas alterações ocorrem, sendo uma delas o aumento da taxa respiratória (CHITARRA e CHITARRA, 2005). 
A degradação da clorofila, bem como o aumento na quantidade de carotenoides ocorrem simultaneamente ao climatério. Isso caracteriza mudança na coloração do exocarpo dos frutos de verde-escuro do pré-climatério para verde-claro no mínimo-climatério, passando ao amareloalaranjado no pico climatério com manutenção dessa cor no pós-climatério. A transformação da cor verde para amarelo-alaranjado nos frutos de cajazeira foi considerada indicativo importante da sua maturidade fisiológica (SAMPAIO, 2002). Segundo Thomas e Janave (1992), a perda da cor verde dos frutos resulta da quebra da estrutura da clorofila, causada principalmente pelas mudanças de $\mathrm{pH}$, presença de sistemas oxidantes e pela atividade de clorofilases. Desta forma, a transformação da coloração ocorre pela revelação e síntese de pigmentos estáveis pertencentes ao grupo dos carotenoides, que permanecem nos tecidos durante a senescência (LEE, 1985).

O teor de sólidos solúveis aumenta durante o amadurecimento do cajá. Sampaio (2002) observou variação de $12,06^{\circ}$ Brix no estádio inicial a $13,69^{\circ}$ Brix no pico climatérico, sem diferenças significativas entre os estádios de maturação. Alves, Filgueiras e Moura (2000) verificaram aumento significativo para esse parâmetro, ou seja, de $8,36 \%$ no estádio inicial para $11,56 \%$ no estádio maduro. Durante o amadurecimento dos frutos ocorre elevação progressiva do teor de sólidos solúveis totais em decorrência da transformação dos polissacarídeos insolúveis em açúcares solúveis (MELO, LIMA e NASCIMENTO, 2000).

A maturação dos frutos pode ser definida como a sequência de mudanças na cor, aroma e textura que conduzem ao estado comestível, tornando-os apropriados para o consumo in natura e/ ou para a industrialização (CHITARRA e CHITARRA, 2005).

O conteúdo de sólidos solúveis totais (SST) e a acidez total titulável (ATT) no final da maturação dos frutos indicam polpa de sabor adocicado e acentuadamente ácido. Os açúcares redutores representam aproximadamente $90 \%$ dos açúcares solúveis totais no final da maturação (ALVES, FILGUEIRAS e MOURA, 2000). Somando os resultados de rendimento em polpa e amido, esses autores mostraram que o cajá atinge qualidade máxima para o consumo ou industrialização ao final da maturação. Antes disso, há comprometimento principalmente do seu sabor pela excessiva acidez e alto teor de amido. Observam ainda poucas variações no teor de pectina quando analisaram a polpa integral, assim como na atividade enzimática e nos teores de compostos fenólicos. Porém, o fracionamento das pectinas mostrou maior solubilidade com o amadurecimento.

Em estudo realizado por Costa (1998), o uso de atmosfera modificada reduziu significativamente a perda de peso nos frutos durante o armazenamento, notadamente quando realizado sob refrigeração. $O$ armazenamento do cajá em temperatura ambiente revelou que após dois dias de já havia desenvolvimento de fungos nas amostras que permaneceram em condições aceitáveis de consumo apenas por um dia. O armazenamento sob refrigeração revelou que o cajá se conservou em condições aceitáveis de processamento para indústria por até cinco dias em atmosfera ambiente e para o consumo in natura por até dois dias. Já em refrigeração com atmosfera modificada, os frutos permaneceram em condições aceitáveis de processamento para a indústria durante dez dias e para o consumo in natura por até oito dias. A partir de então, os frutos começaram a apresentar sintomas de injúria pelo frio evidenciando que a temperatura de $8^{\circ} \mathrm{C}$ não é adequada ao armazenamento de cajá.

Os frutos tropicais com altas taxas respiratórias não toleram temperaturas muito baixas e podem ser conservados apenas por curto período de tempo. Logo após a colheita, na fase préclimatérica, o fruto deve ser colocado rapidamente na temperatura ideal de conservação para diminuir sua respiração. Quanto mais curto o intervalo de tempo entre a colheita e o abaixamento da temperatura, melhor e mais longa será a conservação dos frutos (CHITARRA e CHITARRA, 2005).

Mata, Braga e Silva (2003) consideraram o processo de congelamento dos frutos de cajá 
como forma eficaz de evitar a perecibilidade e controlar a sazonalidade. O cajá levou 75 minutos para ser congelado a $-30^{\circ} \mathrm{C}, 44$ minutos à temperatura de $-60^{\circ} \mathrm{C}$ e 40 minutos à temperatura de $-90^{\circ} \mathrm{C}$. A difusividade térmica, durante o congelamento, variou de $2,8.10^{-7} \mathrm{~m}^{2} \mathrm{~s}^{-1}$ a $3,452.10^{-7} \mathrm{~m}^{2} \mathrm{~s}^{-1}$ na fase de resfriamento e de 3,1082.10-7m²s-1 a 3,2539.10-7 $\mathrm{m}^{2} \mathrm{~s}-1$ na fase do pós-congelamento. Em trabalho posterior, tais autores reportaram que a densidade da polpa de cajá aumenta de 920 para $1.253 \mathrm{~kg} \cdot \mathrm{m}^{-3} \mathrm{com}$ a variação da temperatura de -18 para $-196^{\circ} \mathrm{C}$ e também em função da elevação do teor de sólidos solúveis totais de $9^{\circ}$ Brix para $60^{\circ}$ Brix. O calor específico da polpa de cajá diminui com a redução de temperatura e aumenta com a concentração de sólidos solúveis totais, sendo o menor valor obtido de $1,646 \mathrm{~kJ} \mathrm{~kg}^{-1}{ }^{\circ} \mathrm{C}^{-1} \mathrm{a}-196^{\circ} \mathrm{C}$ e $9^{\circ}$ Brix e o maior de $3,677 \mathrm{~kJ} \mathrm{~kg}^{-1}{ }^{\circ} \mathrm{C}-1$ para $-18^{\circ} \mathrm{C}$ e $60^{\circ}$ Brix (MATA, DUARTE e ZANINI, 2005).

\section{CARACTERIZAÇÃO DA POLPA}

Maciel e Guerra (2008) consideraram o cajá rica fonte de fitoquímicos, muitos dos quais com importância fisiológica, a exemplo das antocianinas, dos carotenoides, fenólicos, flavonoides e ácido ascórbico. Esses compostos encontram-se frequentemente em frutos e vêm sendo motivo de investigações científicas por apresentarem propriedades antioxidantes. A Tabela 2 apresenta o resumo da diversidade de dados sobre características físico-químicas e bioquímicas da polpa de cajá.

A acidez constitui importante parâmetro para a apreciação do estado de conservação de produtos alimentícios. O processo de decomposição, seja por hidrólise, oxidação ou fermentação, geralmente, altera a concentração dos íons de hidrogênio e por consequência a acidez do produto.

Para a polpa de cajá, a legislação vigente estipula os valores mínimos de 2,2 para pH e $0,90 \%$ para acidez total, conforme os padrões de identidade e qualidade (BRASIL, 2000).

Os minerais, grupo de elementos largamente distribuídos na natureza, exercem papel fundamental em diversas funções do organismo humano. As frutas, em geral, apresentam em sua composição grande variedade de sais minerais essenciais, representando rica contribuição para a dieta (FRANCO, 1992).

Segundo Mattietto (2005), a análise mineralógica da polpa de cajá in natura mostrou destaque quanto aos teores de potássio, ferro, manganês e cobre. A adição da casca à polpa promoveu aumento significativo nos teores de potássio e cálcio.

Sacramento e Souza (2000) reportaram que os frutos de cajá são fontes das vitaminas A, B1, B2, C e niacina. Rodriguez-Amaya e Kimura (1989) sinalizaram que o cajá pode ser considerado boa fonte de provitamina A, com a polpa fornecendo o valor de $135 \mathrm{RE} .100 \mathrm{~g}^{-1}$.

A composição de carotenoides e vitamina $\mathrm{A}$ em produtos comerciais de cajá (Spondias lutea L.), como polpas congeladas e sucos pasteurizados, foi determinada por Hamano e Mercadante (2001) mediante cromatografia a líquido de alta eficiência. Os produtos continham os seguintes carotenoides: phytoene, phytofluene, all-trans- $\beta$-caroteno, 13-cis- $\beta$-caroteno, 9-cis- $\beta$ caroteno, $\alpha$-caroteno, $\beta$-criptoxantina (cis e trans), zeinoxantina e luteína. $O$ principal carotenoide $\beta$-criptoxantina variou de 5,54 a 8,19 ( $\mathrm{g} / \mathrm{g}$ ), seguido pela luteína (de 3,52 a $6,16 \mathrm{~g} / \mathrm{g}$ ) e zeinoxantina (de 3,52 a $3,85 \mathrm{~g} / \mathrm{g}$ ).

Mendes et al. (2008) verificaram que o cajá apresentou valores entre 13,0 e $31,0 \mathrm{mg} / 100 \mathrm{~g}$ de antocianinas totais, com média total de $20,2 \mathrm{mg} / 100 \mathrm{~g}$. No que diz respeito aos teores de carotenoides totais, as polpas de cajá apresentaram valores entre 50,1 a 65,0 mg/100 g, com média total de $57,2 \mathrm{mg} / 100 \mathrm{~g}$. Afirmaram que a polpa de cajá, além das propriedades nutricionais, apresenta propriedades funcionais bastante desejáveis, principalmente pelos expressivos teores de carotenoides encontrados. Isto torna o cajá promissora fonte de compostos antioxidantes, cujo consumo deveria ser estimulado. 


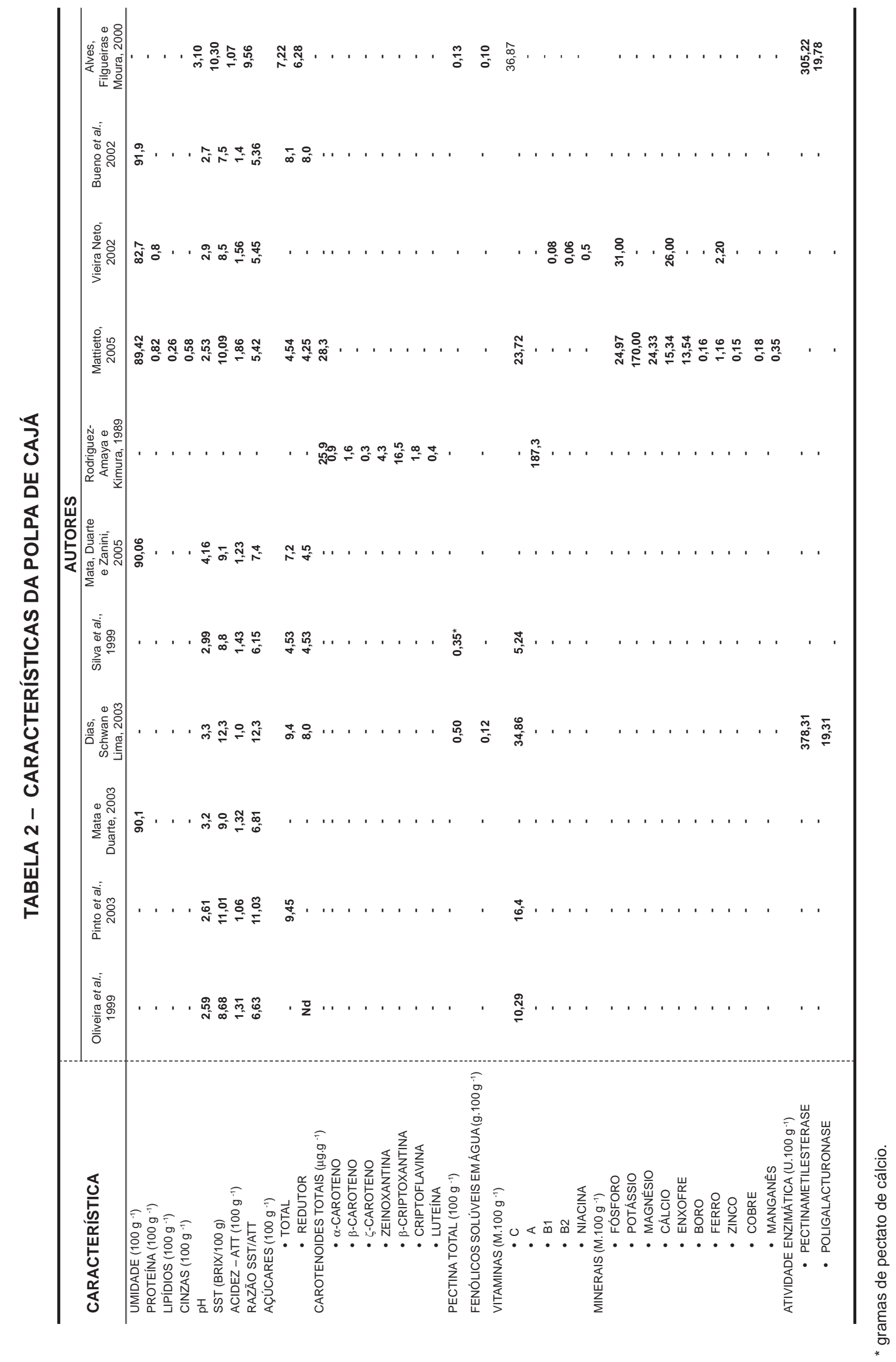


Segundo Kimura (1989) foram detectados e identificados sete carotenoides no cajá: $\alpha$-caroteno, $\beta$-caroteno, $\gamma$-caroteno, zeinoxantina, criptoxantina, criptoflavina e luteína. A $\beta$-criptoxantina contribui de forma marcante para o valor de vitamina $A$, perfazendo $74 \%$ do total na polpa e na casca.

De acordo com Rodrigues-Amaya e Pastore (1997), a degradação de pequena parte dos carotenoides é desejável e leva a formação de compostos voláteis que contribuem para o aroma e o sabor típico de cada fruto.

O cajá encontra-se entre as inúmeras frutas tropicais e subtropicais produzidas no Brasil que se destacam sob o ponto de vista do aroma da polpa. Narain et al. (2004) constataram 33 compostos voláteis na polpa de cajá, sendo as principais classes os ésteres (48,7\%), alcóois $(21,7 \%)$, aldeídos $(11,6 \%)$ e cetonas $(4,19 \%)$. Além desses, os compostos aromáticos característicos foram: $\gamma$ - octalactona e os ácidos butírico e hexanoico.

Ceva-Antunes (2003) identificou e comparou a composição volátil de taperebá e de cajá coletados em suas regiões nativas (o estado do Pará e o estado do Ceará, respectivamente), utilizando as metodologias de microextração em fase sólida (MEFS) e destilação e extração simultânea (DES). Por DES foi possível identificar 30 compostos idênticos em ambas as frutas e por MEFS 32. Nas duas frutas, as classes predominantes foram os hidrocarbonetos e os ésteres. Os compostos principais no cajá foram butirato de butila, hexanoato de etila e mirceno, enquanto no taperebá foram butanoato de etila e (Z) cariofileno.

A presença de pectinases endógenas é comum em frutas. Dias, Schwan e Lima (2003) encontraram 19,32 U de poligalacturonase e 378,31U de pectinametilesterase em polpas de cajá obtidas a partir de frutos colhidos em vários municípios das regiões Norte e Nordeste. Esses autores consideraram que as atividades pectinolíticas observadas não seriam suficientes para promover redução da viscosidade das polpas.

Furtunato (2002) avaliou o teor de peroxidases em 12 diferentes polpas de frutas e a do

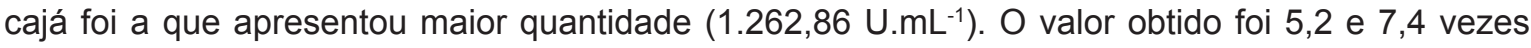
superior as atividades encontradas para polpas de pinha e sapoti, respectivamente. Pereira e Sato (2001) encontraram 58.560 U. . ${ }^{-1}$ em polpa de taperebá, a denominação amazônica das variedades de cajá.

\section{PROCESSAMENTO DE CAJÁ}

Na Figura 1 são citados alguns processamentos utilizando o cajá, espécie com grande potencial para exploração agroindustrial.

\subsection{POLPA}

O aproveitamento de frutas na forma de polpa congelada proporciona a possibilidade de utilização de frutas pouco conhecidas, como as provenientes do Cerrado e das regiões Norte e Nordeste, que já despertam interesse do mercado externo (MATTA et al., 2005).

A produção de polpa de fruta congelada, antes concentrada na região Nordeste, expandiuse por todo o território nacional. Trata-se de segmento que, apesar de englobar grandes indústrias, está caracterizado pela presença de micro e pequenas empresas (MATTA et al., 2005).

A polpa de fruta congelada está em expansão no mercado de sucos de frutas tropicais, cuja procura vem crescendo substancialmente tanto para consumo doméstico, como em lanchonetes e restaurantes. Motivado pelo movimento ecológico em virtude do aspecto natural do produto verificase a tendência de substituição dos sucos engarrafados pela polpa de fruta congelada, que se atribui a dois fatores importantes: a) não utilização de aditivos químicos na conservação do produto; b) menor preço de venda em função de menor custo de produção (SEBRAE, 1997). 


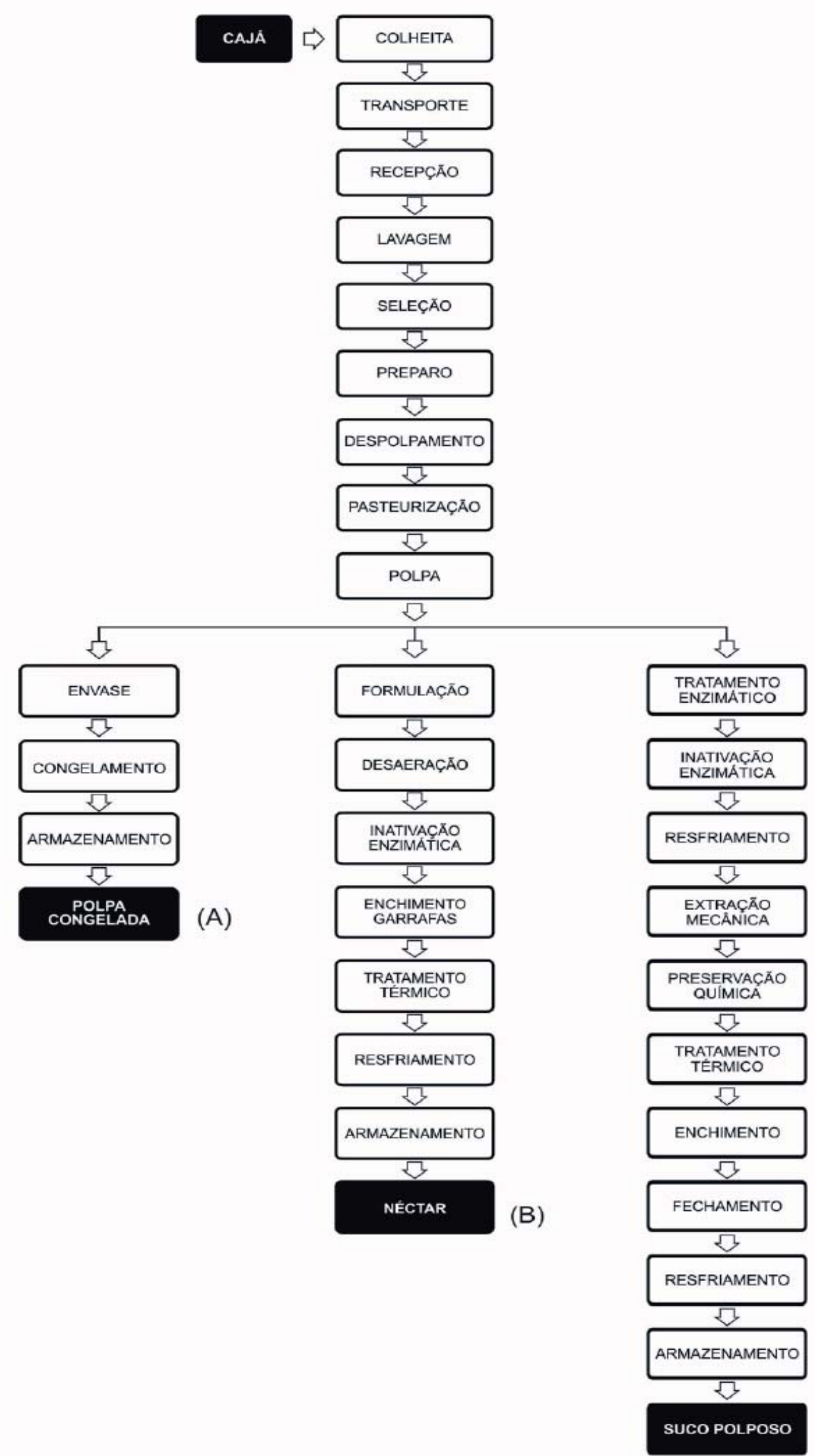

(C)

FIGURA 1 - FLUXOGRAMA DE ALGUNS PROCESSAMENTOS UTILIZANDO O CAJÁ

(A) POLPA CONGELADA (FONTE: SILVA, 1995b), (B) NÉCTAR E (C) SUCO POLPOSO (FONTE: SILVA, 1995a). 
Importante característica do mercado brasileiro de sucos é sua extraordinária oferta dos mais variados tipos de frutos. Segundo dados da AC Nielsen, em 2004 o mercado de sucos prontos cresceu $15,6 \%$ e atingiu proporções maiores do que o de refrigerantes, cujo aumento foi de apenas $6,5 \%$ (MAIA, SOUZA e LIMA, 2007).

Além dos tradicionais refrescos em pó e refrigerantes que os brasileiros consumiam até o final da década de 90, surgiram três novas linhas: a de refrescos prontos, néctares e os sucos de frutas. A diferença está na concentração da polpa de fruta, variando também o preço e, por consequência, o público-alvo. Segundo padrões estabelecidos no Brasil, a composição dos refrescos prontos tem até $15 \%$ de polpa de fruta, passando para $45 \%$ nos néctares e até $65 \%$ nos sucos. Internacionalmente, o índice para sucos pode chegar até $80 \%$ de polpa (ARAUJO, 2004).

As frutas desempenham importante papel na saúde humana, contribuindo para o fornecimento de calorias, sais minerais, vitaminas, fibras e água. As características físico-químicas das frutas de determinada espécie variam, além do fator genético, com o local, a época de colheita, o estádio de maturação, os tratos culturais, etc (SACRAMENTO e SOUZA, 2000).

O Ministério da Agricultura, Pecuária e Abastecimento (MAPA) define polpa de fruta como o produto não fermentado, não concentrado, não diluído, obtido de frutos polposos, através de processo tecnológico adequado, com teor mínimo de sólidos totais, proveniente da parte comestível do fruto. O MAPA também estabelece padrões de identidade e qualidade para a polpa ou purê de cajá, cujas características estão descritas na Tabela 3 (BRASIL, 2000).

\section{TABELA 3 - PADRÕES DE IDENTIDADE E QUALIDADE DA POLPA OU PURÊ \\ DE CAJÁ (BRASIL, 2000)}

\begin{tabular}{lcc}
\hline CARACTERí́sTICA & DESCRITOR \\
\hline Cor & \multicolumn{2}{c}{ Amarela } \\
Sabor & \multicolumn{2}{c}{ Ácido } \\
Aroma & Próprio \\
\hline \multicolumn{2}{c}{ Mínimo } & Máximo \\
\hline Sólidos solúveis em ${ }^{\circ}$ Brix, a $20^{\circ} \mathrm{C}$ & 9,00 & - \\
pH & 2,2 & - \\
Acidez total expressa em ácido cítrico $(\mathrm{g} / 100 \mathrm{~g})$ & 0,90 & 12,00 \\
Açúcares totais naturais do cajá $(\mathrm{g} / 100 \mathrm{~g})$ & - & - \\
Sólidos totais $(\mathrm{g} / 100 \mathrm{~g})$ & 9,50 & \\
\hline
\end{tabular}

De acordo com Barbosa, Nazaré e Hashimoto (1981), apud Sacramento (2000), o percentual médio de rendimento em polpa ou suco de cajá é de $40 \%$ e poderá ser compensado pelas pronunciadas características de odor e sabor com amplas possibilidades industriais na fabricação de sucos, néctares e sorvetes. A avaliação química dos frutos in natura mostrou que o teor de acidez e o $\mathrm{pH}$ favorecem grandemente sua conservação, quer pelo congelamento dos frutos integrais ou pelo processamento térmico do suco ou néctar.

No Sul da Bahia foi constatado rendimento industrial entre 55 a $60 \%$ de polpa, dependendo da seleção efetuada antes do processamento. $\mathrm{Na}$ avaliação de amostras de frutos em diversas cajazeiras foram obtidos rendimentos médios de polpa variando de 56,07 a 73,27\% (SACRAMENTO e SOUZA, 2000).

Moura (2009) estudou a maceração enzimática da polpa de cajá, utilizando a preparação Viscozyme L para a redução da sua consistência. Afirmou que a adição de 2000 ppm de preparação 
enzimática à polpa integral, macerada por 1 hora, favoreceu a redução da sua consistência.

De acordo com Dias, Schwan e Lima (2003), a pequena quantidade de atividade das poligalacturonases encontradas na polpa de cajá não é suficiente para a redução da sua viscosidade, sendo necessária a adição do complexo enzimático. Furtunato (2002) verificou a presença de $11 \times 10^{4}$ U. $\mathrm{mL}^{-1}$ de pectinestease em polpa de cajá, obtida a partir de frutos adquiridos no mercado de Natal (RN). A elevada acidez da polpa de cajá estudada favoreceu a inativação térmica da pectinesterase, que a $40^{\circ} \mathrm{C}$ foi imediatamente inativada após tempo de retardo. Foram observadas duas frações da enzima pectinesterase, uma termorresistente e outra termolábil. A pectinesterase foi menos resistente ao tratamento térmico que a peroxidase, comprovando-se o efeito da temperatura sobre o tempo de aquecimento necessário à inativação térmica da peroxidase. Para a definição dos parâmetros de processamento térmico de polpas de frutas, sua acidez deve ser considerada, tendo em vista que influencia o comportamento de inativação térmica de enzimas termorresistentes presentes.

Os frutos da cajazeira destinados para a industrialização passam por processo de seleção, sendo avaliados quanto a maturação, firmeza, machucaduras, defeitos causados por fungos, roedores e insetos. Após os frutos são submetidos à imersão em água com elevadas concentrações de cloro (de 10 a 50 ppm) e seguem ao despolpamento mediante esmagamento de suas partes comestíveis, sendo passadas em peneiras (filtros) com furos diversos. O refino serve para melhorar o aspecto visual e a estabilidade física do produto que será envasado ou ensacado e congelado. A pasteurização é opcional, sendo a polpa pasteurizada conservada entre 2 e $7^{\circ} \mathrm{C}$ e a não pasteurizada a $-18^{\circ} \mathrm{C}$ (SACRAMENTO e SOUZA, 2000).

A pasteurização pode ser utilizada por pequenas unidades de processamento para prolongar a vida útil de alimentos. É capaz de conservar polpas de frutas por inativação enzimática e destruição de microrganismos termossensíveis, provocando alterações mínimas em seu valor nutritivo e características sensoriais (FELLOWS, 1994).

Segundo Bastos et al. (2008), a pasteurização ao substituir o congelamento possibilita economia de energia, favorecendo o armazenamento e a distribuição do produto a partir da Região Norte. A técnica pode ser aplicada com eficiência na conservação do produto à temperatura ambiente, com vida-de-prateleira de no mínimo quatro meses.

\subsection{SUCO POLPOSO}

$\mathrm{Na}$ indústria processadora de suco de frutas, a produção e a comercialização dependem das características exigidas pelo mercado para cada tipo de suco. Entre as características préestabelecidas estão os níveis de turbidez, a acidez, os nutrientes presentes e o perfil de aromas (MAIA, SOUZA e LIMA, 2007).

A partir da polpa oriunda de frutos maduros de cajá, diferentes combinações de tempo e concentração enzimática foram estudados visando encontrar os melhores níveis de rendimento de suco polposo. Foi obtido rendimento de $85,908 \%$ com concentração enzimática (Pectinex AR) na ordem de 120 ppm (SILVA, 1995a).

Silva et al. (1997) estudaram a obtenção de suco polposo de cajá por extração mecânicoenzimática. O produto final foi analisado com relação as suas características físico-químicas e perfil sensorial após estocagem de 120 dias à temperatura ambiente $\left(28^{\circ} \mathrm{C}\right)$. A polpa foi tratada com $120 \mathrm{ppm}$ de enzimas pectinolíticas (Pectinex Ultra SP-L) por $30 \mathrm{~min}$, à temperatura de $25^{\circ} \mathrm{C} \mathrm{e}$ $\mathrm{pH}$ natural $(2,98)$, seguido do processo mecânico de extração. Empregaram como processo de preservação do suco integral o método hot-fill + aditivos. Estatisticamente, as características físicoquímicas permaneceram inalteradas ao longo de 120 dias, apresentando os seguintes valores médios: $\mathrm{pH} 2,78$, sólidos solúveis $11,19{ }^{\circ}$ Brix, acidez titulável total $1,46 \mathrm{~g} \%$ de ácido cítrico, açúcares redutores $6,91 \mathrm{~g} \%$ em glicose, taninos $77,36 \mathrm{mg} \%$ de ácido tânico, cor 0,125 em leitura de absorbância a $440 \mathrm{~nm}$, pectina $0,12 \mathrm{~g} \%$ em pectato de cálcio e viscosidade 10,8 cps. 
De acordo com os padrões de identidade e qualidade (BRASIL, 1977), o suco polposo de cajá deve obedecer em sua composição os limites mostrados na Tabela 4.

\section{TABELA 4 - PADRÕES DE IDENTIDADE E QUALIDADE DO SUCO POLPOSO DE CAJÁ (BRASIL, 1977)}

\begin{tabular}{lcc}
\hline & Máximo & Mínimo \\
\hline Densidade relativa a $20^{\circ} \mathrm{C}$ & - & 1,0317 \\
Sólidos solúveis, ${ }^{\circ} \mathrm{Brix} 20^{\circ} \mathrm{C}$ & - & 8,0 \\
Sólidos em suspensão, $\% \mathrm{v} / \mathrm{v}$ & 50,0 & - \\
Álcool etílico, GL a $20^{\circ} \mathrm{C}$ & 0,5 & - \\
Açúcares totais, naturais do cajá $(\mathrm{g} / 100 \mathrm{~g})$ & 12,0 & 1,25 \\
Acidez total expressa em ácido cítrico $(\mathrm{g} / 100 \mathrm{~g})$ & - & \\
\hline
\end{tabular}

\subsection{SUCO CLARIFICADO}

O processo de clarificação de sucos possibilita a oferta de produto nobre, durante o ano todo, além de acompanhar o estilo de vida do consumidor que almeja novos produtos e ampla variedade de escolha (SILVA et al., 1999).

Segundo Cheftel e Cheftel (1977), apud Silva (1995a), quando se deseja suco claro é indispensável eliminar completamente a pectina porque sua presença contribui para manter em suspensão as finas partículas de polpa responsáveis pela turbidez, dificultando o processo de decantação e filtração.

De acordo com Maia, Souza e Lima (2007) durante a etapa de clarificação, o suco é submetido ao tratamento enzimático para degradação das pectinas e do amido e em seguida passa pelo processo de filtração para eliminação dos sólidos em suspensão. O suco resultante apresenta baixa viscosidade durante a concentração permitindo alta taxa de transferência de calor e, consequentemente, que maiores concentrações sejam obtidas.

Silva et al. (1999) estudaram a produção de suco de cajá clarificado. Aplicaram 120 ppm de enzima pectinolítica (Pectinex Ultra SPL) na polpa para obtenção do suco polposo e, em seguida, 500 ppm de enzima pectinolítica (Pectinex-AR) utilizando a "prova do álcool" como indicador da presença de pectina. Para o processo de clarificação do suco empregaram como agentes clarificantes, 400 ppm de gelatina e 500 ppm de sílica sol. A "prova do excesso e/ou da insuficiência de clarificação", bem como a "prova de estabilidade" mostraram resultados negativos, indicando a eficiência do processo de clarificação.

\subsection{NÉCTAR}

No processamento tecnológico do néctar, o melhor produto deve ser constituído de $18 \%$ de suco e 14Brix, não havendo necessidade do emprego de ácido cítrico porque o suco simples já apresenta 1,65\% de acidez total. As perdas durante o processamento estão em torno de apenas 3\% (SACRAMENTO E SOUZA, 2000).

De acordo com os Padrões de Identidade e Qualidade, o néctar de cajá (BRASIL, 2003) destinado ao consumo direto deve obedecer às características e composição apresentadas na Tabela 5. 
TABELA 5 - PADRÕES DE IDENTIDADE E QUALIDADE DO NÉCTAR

DE CAJÁ (BRASIL, 2003)

\begin{tabular}{|c|c|c|}
\hline CARACTERÍSTICA & \multicolumn{2}{|c|}{ DESCRITOR } \\
\hline Cor & \multicolumn{2}{|c|}{ Variando de amarelada a alaranjada } \\
\hline Sabor & \multicolumn{2}{|c|}{ Característico } \\
\hline Aroma & \multicolumn{2}{|c|}{ Próprio } \\
\hline & Mínimo & Máximo \\
\hline Suco ou polpa de cajá (g/100 g) & 25,00 & - \\
\hline Sólidos solúveis em ${ }^{\circ} \mathrm{Brix}$, a $20^{\circ} \mathrm{C}$ & 11,00 & - \\
\hline Acidez total em ácido cítrico (g/100 g) & 0,20 & - \\
\hline Açúcares totais (g/100 g) & 7,00 & - \\
\hline
\end{tabular}

\subsection{FERMENTADO DE CAJÁ}

Dias, Schwan e Lima (2003) estudaram o processo de fermentação a partir do mosto de polpa de cajá para a obtenção de bebida alcoólica e avaliaram sua aceitação. A polpa de cajá foi chaptalizada a $24^{\circ}$ Brix constituindo $20 \mathrm{~L}$ de mosto, desacidificado com $\mathrm{CaCO}_{3}$ a pH 3,8 para ser submetido ao tratamento enzimático com Ultrazym AFP-L. Utilizaram $\mathrm{SO}_{2}$ como agente inibidor do crescimento bacteriano e como antioxidante. O mosto, clarificado com bentonite, foi inoculado com Saccharomyces cerevisiae na concentração de $10^{7}$ células $/ \mathrm{mL}$, sendo a fermentação conduzida a $22^{\circ} \mathrm{C}$ por 10 dias. Ao final da fermentação, o mosto foi armazenado a $10^{\circ} \mathrm{C}$ por 10 dias quando efetuaram a primeira trasfega. A segunda trasfega ocorreu 30 dias após a primeira, antes da filtração. Observaram alta concentração de alcóois superiores, os quais são normalmente responsáveis pela formação de sabor e aroma em bebidas alcoólicas. A boa aceitação da bebida, avaliada por 45 julgadores não treinados, indicou que o fermentado de cajá pode representar nova fonte de investimento para indústrias ou pequenos produtores.

\subsection{BEBIDA LÁCTEA}

Meneses (2011) elaborou bebida láctea fermentada à base de soro de leite e polpa de cajá com potencial atividade probiótica. Diferentes formulações, variando a quantidade de polpa adicionada foram elaboradas. O autor verificou que todas as bebidas analisadas foram bem aceitas pelos consumidores para todos os atributos avaliados no teste sensorial, assim como seu índice de aceitabilidade e intenção de compra. As bebidas lácteas fermentadas sabor cajá, apresentaram-se como alternativa inovadora de utilização dessa fruta em novo produto, demonstrando que a utilização de soro de leite na formulação é viável tecnológica, nutricional e sensorialmente.

\subsection{OUTROS}

A partir da polpa e do suco de cajá podem ser obtidos alguns produtos, como iogurte, sorvete, picolé e geleia, refresco, preparado sólido para refresco, xarope e refrigerante, dentre outros. Alguns dos processamentos citados são estabelecidos pela Portaria 544 que regulamenta os padrões de identidade e qualidade (BRASIL, 1998).

Define-se refresco como a bebida não gaseificada, não fermentada, obtida pela diluição em água potável do suco de fruta, polpa ou extrato vegetal de sua origem, adicionada de açúcares (Tabela 6). 


\section{TABELA 6 - PADRÕES DE IDENTIDADE E QUALIDADE DO REFRESCO \\ DE CAJÁ (BRASIL, 1998)}

\begin{tabular}{l|c|c|c}
\hline & Máx. & & Mín. \\
\cline { 2 - 4 } $\begin{array}{l}\text { Suco de cajá, no mínimo com } 8^{\circ} \text { Brix, \%(VN) } \\
\text { Açúcar }\end{array}$ &.-- & & 20 \\
Acidez titulável, em ácido cítrico, g/100 mL &.-- & qsp & \\
\hline
\end{tabular}

qsp = quantidade suficiente para.

O preparado sólido para refresco é o produto à base de suco ou extrato vegetal de sua origem e açúcares, podendo ser adicionado de edulcorantes hipocalóricos e não calóricos, destinado à elaboração de bebida para o consumo imediato pela adição de água potável (BRASIL, 1998).

Define-se xarope como o produto não gaseificado, obtido pela dissolução em água potável de suco de fruta, polpa ou parte do vegetal e açúcares, numa concentração mínima de $52^{\circ}$ Brix, à $20^{\circ} \mathrm{C}$, adicionado unicamente de água potável para o seu consumo (BRASIL, 1998).

Refrigerante é a bebida gaseificada, obtida pela dissolução em água potável, de suco ou extrato vegetal de sua origem, adicionada de açúcares. O refrigerante deverá ser obrigatoriamente saturado de dióxido de carbono industrialmente puro (BRASIL, 1998).

Vieira (2010) realizou a extração de carotenoides de película comestível de cajá utilizando maceração enzimática com a preparação Pectinex XXL. A razão película:água adequada para a maceração foi de 1:4 e o tempo de trituração mais eficiente de 30s. Demostrou também que é possível extrair carotenoides de película comestível de cajá mediante hidrólise enzimática utilizando meio aquoso. A condição de melhor recuperação de carotenoides foi $150 \mu \mathrm{L}$ do complexo enzimático, $3 \mathrm{~h}$ de maceração e temperatura de $35^{\circ} \mathrm{C}$.

\section{CONSIDERAÇÕES FINAIS}

É crescente o interesse pela fruta e produtos derivados do cajá, devido ao seu sabor e aroma agradáveis. No entanto, além de problemas com a produção, concentrada em duas regiões, insuficiente para suprir a demanda do mercado e da exploração extrativista, também se observa reduzido nível de conhecimentos tecnológicos acumulados nas áreas de nutrição e processamento. A comercialização da fruta ainda ocorre basicamente em nível local, destinando-se a produção de polpa congelada, suco, sorvete, picolé e geleia, dentre outros. Contudo faz-se necessário organizar ações de pesquisa que visem aumentar o conhecimento sobre as características nutricionais dessa fruta, bem como sobre o desenvolvimento de novos processos tecnológicos ou ajustes naqueles já existentes, a fim de permitir o surgimento de novos produtos e a ampliação de mercados, o que por consequência levaria ao adensamento e estruturação da cadeia produtiva.

\section{ABSTRACT}

\section{PROCESSING AND UTILIZATION OF YELLOW MOMBIN FRUIT PULP}

The present review aimed to gather information on national and international scientific literature concerning physical, physicochemical and sensory characteristics of yellow mombin fruit and its products, like juices, nectars and fermented beverages. It was verified that an organization of research actions are required to expand knowledge concerning the nutritional characteristics of this fruit, as well as about the development of new technological processes, or regulation of the existing ones, to aloud the emergence of new products and a market expansion, resulting on a densification and organization of the supply chain. 


\section{REFERÊNCIAS}

1 ALVES, R. E.; FILGUEIRAS, H. A. C.; MOURA, C. F. H. Caracterização de frutas nativas da América Latina. Jaboticabal: Funep, 2000. 66 p. (Série Frutas Nativas, 9).

2 ARAUJO, A. Sucos: mercado que cresce 25\% a cada ano. Brasil Alimentos, n. 24, p.18-22, mar./abr. 2004.

3 BARBOSA, W.C.; NAZARÉ, R.F.R.; HASHIMOTO, K. Estudo bromatológico e tecnológico da graviola e do taperebá. Belém: Embrapa/CPATU, 1981.16 p. (Boletim de Pesquisa, 32).

4 BASTOS, C.T.R.M.; LADEIRA, T.M.S.; ROGEZ, H.; PENA, R.S. Estudo da eficiência da pasteurização da polpa de taperebá (Spondias mombin). Alimentos e Nutrição, Araraquara, v. 19, n. 2, p. 123-131, abr./jun. 2008.

5 BOSCO, J.; SOARES, K. T.; AGUIAR FILHO, S. P. de; BARROS, R. V. A cultura da cajazeira. João Pessoa: EMEPA, 2000. 29 p. (Documentos, 28).

6 BRASIL. Ministério da Agricultura e do Abastecimento. Portaria n. 544, de 16 de Novembro de 1998. Aprova regulamentos técnicos para fixação dos padrões de identidade e qualidade para refresco, refrigerante, preparado ou concentrado líquido para refresco ou refrigerante, preparado sólido para refresco, xarope e chá pronto para o consumo. Diário Oficial [da] República Federativa do Brasil, Brasília, DF, 17 de novembro de 1998. Seção 1, p. 2197-2200.

7 BRASIL. Ministério da Agricultura e do Abastecimento. Instrução Normativa n. 1, de 07 de janeiro de 2000. Regulamento técnico geral para fixação dos padrões de identidade e qualidade para polpa de fruta. Diário Oficial [da] República Federativa do Brasil, Brasília, 10 de janeiro de 2000, Seção 1, p. 54.

8 BRASIL. Ministério da Agricultura e do Abastecimento. Instrução Normativa n. 12, de 04 de setembro de 2003. Regulamento técnico para fixação dos padrões de identidade e qualidade gerais para suco tropical de abacaxi, acerola, cajá, caju, goiaba, graviola, mamão, manga, mangaba, maracujá e pitanga; e os padrões de identidade e qualidade dos néctares de abacaxi, acerola, cajá, caju, goiaba, graviola, mamão, manga, maracujá, pêssego e pitanga. Diário Oficial [da] República Federativa do Brasil, Brasília, 09 de setembro de 2003. Seção 1, p. 2.

9 BUENO, S. M.; LOPES, M. do R. V.; GRACIANO, R. A. S; FERNANDES, E. C. B.; GARCIA-CRUZ, C. H. Avaliação da qualidade de polpas de frutas congeladas. Revista do Instituto Adolfo Lutz, São José do Rio Preto, v.62, n.2, p. 121126, 2002.

10 CEVA-ANTUNES, P. M.N. Análise da composição volátil do taperebá (Spondias mombin L.), cajá (Spondias mombin L.) e siriguela (Spondias purpúrea). 2003. 107 f. Tese (Doutorado em Ciência de Alimentos) - Universidade Federal do Rio de Janeiro, Rio de janeiro, 2003.

11 CHEFTEL, J.C; CHEFTEL, H. Introducción a la bioquímica de los alimentos. Zarogoza: Acribia, 1977. v.1, 213 p.

12 CHITARRA, M.I.F.; CHITARRA, A.B. Pós-colheita de frutos e hortaliças: fisiologia e manuseio. Lavras: UFLA, 2005. $785 \mathrm{p}$.

13 COSTA, N. P. da. Desenvolvimento, maturação e conservação pós-colheita de frutos da cajazeira (Spondias mombim L.).1998. 97 f. (Mestrado em Agronomia) - Universidade Federal da Paraíba, João Pessoa, 1998.

14 DIAS, D. R.; SCHWAN, R. F.; LIMA, L. C. O. Metodologia para elaboração de fermentado de cajá (Spondias mombin L.) Revista Ciência e Tecnologia de Alimentos, Campinas, v.23, n.3, p. 342-350, set.-dez. 2003.

15 FELLOWS, P. Tecnologia del procesado de los alimentos: principios y prácticas. Zaragoza: Acribia, 1994. 549 p.

16 FRANCO, G. Tabela de composição química dos alimentos. 9. ed. Rio de Janeiro: Atheneu Editora, 1992. 307 p.

17 FURTUNATO, A. A. Estudo da cinética de inativação térmica da pectinesterase e da peroxidase presentes na polpa de cajá (Spondias lutea). 2002. 76 f. (Mestrado em Engenharia Química) - Universidade Federal do Rio Grande do Norte, Natal, 2002.

18 HAMANO, P. S.; MERCADANTE, A. Z. Composition of carotenoids from commercial products of caja (Spondias lutea). Journal of Food Composition and Analysis, v.14, p.335-343, 2001.

19 KIMURA, M. Reavaliação de métodos analíticos e determinação da composição de carotenóides e valor de vitamina A em mamão e cajá.1989. 120 f. (Mestrado em Ciência de Alimentos) - Universidade Estadual de Campinas, Campinas, 1989.

20 LEDERMAN, I. E.; BEZERRA, J.E.F.; ASCHOFF, M.N.A.; SOUZA, I.A.de M.; MOURA, R.J.M. de. Oferta e procedência de frutas tropicais e exóticas na CEASA - Pernambuco. Revista Brasileira de Fruticultura, Cruz das Almas, v.14, n.3, p. 203-209, 1992.

21 LEE, C.Y. Changes in carotenoids content of carrots during growth and post-harvest storage. Food Chemistry, v.20, p. 285-293. 1985 
22 MACIEL, M. I. S.; GUERRA, I.C.S. Usos e aplicações de Spondias: processamento e industrialização. In: SIMPÓSIO BRASILEIRO SOBRE UMBU, CAJÁ E ESPÉCIES AFINS, 20., 2008, Recife. Anais... Recife: Empresa Pernambucana de Pesquisa Agropecuária - IPA/UFRPE, 2008. 180 p.

23 MAIA, G. A.; SOUZA, P. H. M. de; LIMA, A. da S. Processamento de sucos de frutas tropicais. Fortaleza: Edições UFC, 2007. 320 p. v.1

24 MATA, M. E. R. M. C.; BRAGA, M. E. D.; SILVA, M. da. Curvas de congelamento de frutos de cajá (Spondias lutea I.) a temperaturas semi-criogênicas. Revista Brasileira de Produtos Agroindustriais, Campina Grande, Especial, n.1, p.5562, ago. 2003

25 MATA, M. E. R. M. C.; DUARTE, M. E. M. Calor específico da polpa de cajá a temperaturas criogênicas e diferentes concentrações de sólidos solúveis: métodos das misturas. Revista Brasileira de Produtos Agroindustriais, Campina Grande, Especial, n.1, p.1-7, 2003

26 MATA, M. E. R. M. C.; DUARTE, M. E. M.; ZANINI, H. L. H. T. Calor específico e densidade da polpa de cajá (Spondias lutea L.) com diferentes concentrações de sólidos solúveis sob baixas temperaturas. Revista de Engenharia Agrícola, Jaboticabal, v.25, n.2, p.488-498, maio/ago.2005.

27 MATTA, V. M. da; FREIRE JUNIOR, M.; CABRAL, L. M. C.; FURTADO, A. A. L. Polpa de fruta congelada. Brasília,DF: Embrapa Informação Tecnológica, 2005. 35 p. (Embrapa Informação Tecnológica. Agroindústria Familiar)

28 MATTIETTO, R. de A. Estudo tecnológico de um néctar misto de cajá (Spondias lutea L.) e umbu (Spondias tuberosa Arruda Câmara). 2005. 299 f. (Doutorado em Tecnologia de Alimentos) - Universidade Estadual de Campinas, Campinas, 2005

29 MELO, E.A.; LIMA, V.L.A.G.; NASCIMENTO, P.P. Temperatura no armazenamento de pitanga. Scientia Agricola, v.57, n.4. p. 629-634, out./dez. 2000

30 MENDES, L. M. de F. C; NEVES, J. A.; DIAS, L. P.; SILVA, M. de J. M. da; Carotenóides e antocianinas totais em polpas de cajá congeladas (Spondias mombin L.). In: CONGRESSO DE PESQUISA E INOVAÇÃO DA REDE NORTE NORDESTE DE EDUCAÇÃO TECNOLÓGICA, 3., 2008, Fortaleza. Anais... Fortaleza: CEFET-CE, 2008.

31 MENESES, C. S. de. Desenvolvimento de bebida láctea fermentada à base de soro de leite e polpa de cajá (Spondias mombim L.) com potencial atividade probiótica. 2011. 106 f. (Mestrado em Ciência e Tecnologia de Alimentos) - Universidade Federal Rural de Pernambuco, Recife, 2011.

32 MOURA, C. L. A. de. Maceração enzimática da polpa de cajá (Spondias mombin L.), 2009.66 f. (Mestrado em Ciência e Tecnologia de Alimentos) - Universidade Federal do Ceará, Fortaleza, 2009.

33 NARAIN, N.; ALMEIDA, J. das N.; GALVÃO, M. de S.; MADRUGA, M. S.; BRITO, E. S de. Compostos voláteis dos frutos de maracujá (Passiflora edulis forma Flavicarpa) e de cajá (Spondias mombin L.) obtidos pela técnica de headspace dinâmico. Revista Ciência e Tecnologia de Alimentos, Campinas, v.24, n.2, p. 212-216, abr./jun. 2004

34 OLIVEIRA, M. E. B. de; BASTOS, M. do S. R. ; FEITOSA, T.; BRANCO, M. A. de A. C.; SILVA, M. das G. G. da. Avaliação de parâmetros de qualidade físico-químicos de polpas congeladas de acerola, cajá e caju. Revista Ciência e Tecnologia de Alimentos, Campinas, v.19, n.3, p. 326-332, set./dez. 1999.

35 PEREIRA, A. M.; SATO, H. H. Características bioquímicas da peroxidase catiônica de taperebá (Spondias lutea L). In: SIMPÓSIO LATINO AMERICANO DE CIÊNCIA DE ALIMENTOS, 4., 2001, Campinas. Resumos... Campinas: R. Vieira, 2001. v1, p 84

36 PINTO, W. da S.; DANTAS, A. C. V. L.; FONSECA, A. A. O.; LEDO, C. A. da S.; JESUS, S. C. de; CALAFANGE, P. L. P.; ANDRADE, E. M. Caracterização física, físico-química e química de frutos de genótipos de cajazeiras. Pesquisa Agropecuária Brasileira, Brasília, v. 38, n. 9, p. 1059-1066, set. 2003

37 RODRIGUEZ-AMAYA, D. B.; PASTORE, G. M. Ciência de alimentos: avanços e perspectivas na América Latina. In: SIMPÓSIO LATINO AMERICANO DE CIÊNCIA DE ALIMENTOS, 1., 1997. Anais... Campinas: Fundação Cargill, 1997. p.151-155.

38 RODRIGUEZ-AMAYA, D. B.; KIMURA, M. Carotenóides e valor de vitamina A em cajá (Spondias lutea). Revista Ciência e Tecnologia de Alimentos, Campinas, v.9, n.2, p. 148-162, 1989.

39 SACRAMENTO, C. K. do; SOUZA, F. X.; Cajá (Spondias mombin L.), Jabuticabal: Funep, 2000. 42 p. (Série Frutas Nativas, 4).

40 SAMPAIO, E. V. S. B.; PAREYN, F. G. C.; FIGUEIRÔA, J. M.; SANTOS JUNIOR, A. G. Espécies da flora nordestina de importância econômica potencial. Recife: Associação Plantas do Nordeste, 2005. 331 p.

41 SAMPAIO, S. de A. Transformações durante o amadurecimento pós-colheita de frutos de cajazeira (Spondias mombim L.), cirigueleira (Spondias purpurea L.) e mangabeira (Hancornia speciosa Gomes). 2002.78 f. (Mestrado 
em Ciência e Tecnologia de Alimentos) - Universidade Federal da Paraíba, João Pessoa, 2002.

42 SEBRAE. Serviço Brasileiro de Apoio às Micro empresas. Polpa de frutas: perfil industrial. 2. ed. Recife, 1997 (Digitalizado em 2003).

43 SILVA, A. de P. V. da. Processamento e estabilidade de sucos polposo e clarificado de cajá (Spondias lutea L.). 1995. 138 f. (Mestrado em Tecnologia de Alimentos) - Universidade Federal do Ceará, Fortaleza, 1995a.

44 SILVA, A. de P. V. da; MAIA, G. A.; OLIVEIRA, G. S. F. de; FIGUEIREDO, R. W. de; BRASIL,I. M. Estudo da produção do suco clarificado de cajá (Spondias lutea L.). Revista Ciência e Tecnologia de Alimentos, Campinas, v.19, n.1, p. 326332, jan.-abr. 1999.

45 SILVA, A. de P. V. da; MAIA, G. A.; OLIVEIRA, G. S. F. de; FIGUEIREDO, R. W. de; BRASIL, I. M. Características de qualidade do suco polposo de cajá (Spondias lutea L.) obtido por extração mecânico-enzimática. Revista Ciência e Tecnologia de Alimentos, Campinas, v.17, n.3, p. 233-236, set./dez. 1997.

46 SILVA, C. A. B. da. Produção de polpa de fruta: tratada termicamente e congelada. Brasília, DF: MAARA-SDR, $1995 \mathrm{~b}$. 30 p. (Série Perfis Agroindustriais).

47 SOARES, E. B.. et al. Caracterização física e química de frutos de cajazeira. Revista Brasileira de Fruticultura, v.28, n.3, p.518-519, dez. 2006.

48 THOMAS, P.; JANAVE, M.T. Effect of temperature on chlorophyllase activity degradation and carotenoids of Cavendish during ripening. International Journal of Food Science and Technology, v. 27, p. 56-63, 1992.

49 VIEIRA NETO, R. D. Frutíferas potenciais para os tabuleiros costeiros e baixadas litorâneas. Aracaju: Embrapa Tabuleiros Costeiros/Empresa de Desenvolvimento Agropecuário de Sergipe - Emdagro, 2002. cap.2, 216 p.

50 VIEIRA, J. M. M., Maceração enzimática de película comestível de cajá (Spondias mombin L.) para a extração de carotenóides. 2010. 53 f. (Mestrado em Engenharia Química) - Universidade Federal do Ceará, Fortaleza, 2010. 